\title{
VISCERAL LEISHMANIASIS IN NON-ENDEMIC DISTRICTS OF BANGLADESH: KNOWLEDGE GAP, ATTITUDE AND PRACTICE OF INHABITANTS AND PROFESSIONALS FOR TREATMENT, PREVENTION AND CONTROL
}

\author{
Hamida Khanum*, Sultan-uz-Zaman, Sabina Yesmin, Sharmin Musa, \\ Hasina Banu and Tuhinur Arju \\ Department of Zoology, Parasitology Branch, Faculty of Biological Sciences \\ University of Dhaka, Dhaka-1000, Bangladesh
}

\begin{abstract}
Investigation on knowledge, attitude and practice (KAP) of inhabitants and professionals for treatment, prevention and control of visceral leishmaniasis carried out on 519 inhabitants and 92 professionals of 6 districts (Panchagarh, Thakurgaon, Dinajpur, Bogra, Pabna and Shirajgonj) of Bangladesh. About $79.2 \%$ inhabitants agreed that they have heard about kala-azar disease. Regarding the transmission of kala-azar, $22.7 \%$ respondents answered by mosquito, about $38.3 \%$ said long period and irregular fever, $7.5 \%$ inhabitants knew enlargement of spleen and liver as sign and symptom of kala-azar. Among the professionals, about $80.4 \%$ of them have the correct knowledge regarding the specific agent (Leishmania donovani) of kalaazar. Investigation on knowledge, attitude and practice (KAP) of inhabitants and professional, $89.1 \%$ and $69.6 \%$ believe that spleen and liver are affected in kala-azar, $39.1 \%$ to $51.1 \%$ professionals understand that lymph nodes, blood and skin are involved as tissues due to kalaazar. Among the professionals, about $80.4 \%$ of them have the correct knowledge regarding the specific agent (L. donovani) of kala-azar.
\end{abstract}

Key words: Visceral leishmaniasis, KAP, symptoms, treatment, prevention and control.

\section{INTRODUCTION}

Kala-azar is a disease of reticulo-endothelial system of vertebrate (man), transmitted through the bite of sand fly where the promastigote form develop. The disease is mainly prevalent in rural areas where the people are living in substandard and unhygienic condition. Visceral leishmaniasis (VL), also known as kala-azar and black fever, is the most severe form of leishmaniasis is caused by protozoan parasite Leishmania donovani. Three clinically distinct leishmaniasis are recognized namely visceral leishmaniasis, cutaneous leishmaniasis and mucocutaneous leishmaniasis. The organism in visceral leishmaniasis was first described in 1903 by Leishman, who examined the spleen of a British soldier with kala-azar who had been stationed Dum-Dum (Shanmugham et al. 1977).

*Corresponding author: hamida_khanum@yahoo.com

(C) 2015 Zoological Society of Bangladesh DOI: 10.3329/bjz.v43i2.27391 
It is the second -largest parasitic killer in the world (after malaria), responsible for an estimated 500,000 deaths each year worldwide (WHO 1993). The parasite affect the internal organs such as liver, spleen (hence 'visceral') and bone marrow and if left untreated will almost always result in the death of the host (Hossain et al. 1994). It is a disease of reticulo-endothelial system (RES) characterized by chronic irregular fever with progressive enlargement of the spleen and to a lesser extent liver, wasting of the body, anaemia, progressive leucopenia, raised erythrocyte sedimentation rate (ESR) (WHO 1993). The methods of transmission include congenital infection, blood transfusion and handling during inoculation of $L$. donovani (Chatterjee 1995). Kala-azar is prevalent in many parts of the world. Five countries, namely, Sudan, Nepal, India, Bangladesh and Brazil account for $90 \%$ of the global cases. Kala-azar affects largely the socially marginalized and the poorest communities (Mondal et al. 2008 ).

Kala-azar is one of the major public health problems in Bangladesh and the disease is endemic in Mymenshign division for few decades (Mondal et al. 2008). During the 'Malaria Eradication Program' through DDT spraying controlled all the transmission of vector borne diseases like malaria, kala-azar, filaria and dengue. In Bangladesh, kala-azar was a rarity in 1960s due to collateral effect of malaria eradication program of sand fly vector (Rahman 1983). But sporadic cases of kala-azar and dermal leishmaniasis were reported from Bangladesh and other parts of Bangladesh (Rahman and Islam 1989). During 1981-85 only 8 upazillas reported kala-azar which increased to 105 upazillas in 2004. During last few decades kala-azar has taken a shape of epidemic proportion with the number of cases according to the reported cases (Bern et al. 2007).

The new areas are being invaded every year posing a challenge for the control of kala-azar program (Bern et al. 2006). It is difficult to plot accurately the present geographical distribution of kala-azar and to determine their prevalence in man. Environmental and other changes may eliminate in some highly endemic foci or conversely may increase its prevalence in others. Though, the geographical distribution is worldwide except Australia, the local endemicity is usually sharply declined (Bern et al. 2006, 2007). In Bangladesh, most of the studies were conducted among susceptible cases and the prevalence of kala-azar was found higher than the present status. In other developing countries, the prevalence was also higher; Shanmugham et al. (1977) reported $50.35 \%$ in Madras, Ali and Ashford (1993) observed 36.4\% in Ethiopia and 26\% in Somalia studied by Shiddo et al. (1995).

In cutaneous form of leishmaniasis, parasites occur in nodules on the face, forearms, inner portion of the thighs and pubic regions. Post-kala-azar dermal leishmaniasis (PKDL) or dermal leishmanoid was first described by Brahmachary in India. Kala-azar is a threat in the public health problem in Bangladesh. It occurs in all age groups and the incidence is related with poor socio-economic conditions (Mondal et al. 2008). The present study was therefore 
undertaken with the objectives - to assess the knowledge, awareness, concept, practices and their attitudes about Kala-azar among general population and health service providers (Professional) in the non-endemic part of Bangladesh.

\section{MATERIAL AND METHODS}

The present study was conducted in the non-endemic northern part of Bangladesh. Five hundred and nineteen inhabitants were selected under 15 upazillas of 6 districts (Panchagarh, Thakurgaon, Dinajpur, Bogra, Pabna and Shirajgonj). The present study was carried out from November 20, 2011 to September 30, 2012. A total of 519 inhabitants were divided in various categories such as- age, sex, occupation, education level, hygienic condition, socio-economic status, use of mosquito net, type of main house, presence and distance of cattle shed from the living room, etc. The study was conducted through direct interrogation of questions from a preset questionnaire.

\section{RESULTS AND DISCUSSION}

A total of 519 inhabitants of selected kala-azar non-endemic areas of 6 districts were carried out during November 20, 2011 to September 30, 2012. The percentages of male respondents were $64.4 \%$ and that of female were $35.6 \%$. In the present observation, regarding the occupation of the inhabitants, the highest $(32.8 \%)$ percentage of house hold heads or respondents have own agriculture field. The second highest were agriculture labors $(22.9 \%)$ and next were business man (18.1\%) and the lowest was housewives (8\%) (Fig: 2).

Among the respondents, according to educational qualification, about $42.2 \%$ were illiterate and $20.8 \%$ were $\mathrm{I}-\mathrm{V}$ class pass, only $3.1 \%$ graduate and 7.3\% self educated (Fig: 3), 15\% respondents were VI-X and $11.6 \%$ SSC/HSC pass. Regarding the distribution of the age-groups of the respondents, highest $(28.9 \%)$ and comparatively the higher $(25.2 \%)$ were in $30-39$ and $40-49$ years age-groups respectively (Fig 1). In the present observation, regarding the houses of the inhabitants, $35.5 \%$ and $33.9 \%$ were mud and tin house respectively, whereas, brick house was only $12.5 \%$ and thatch house was $16.6 \%$ (Table 1).

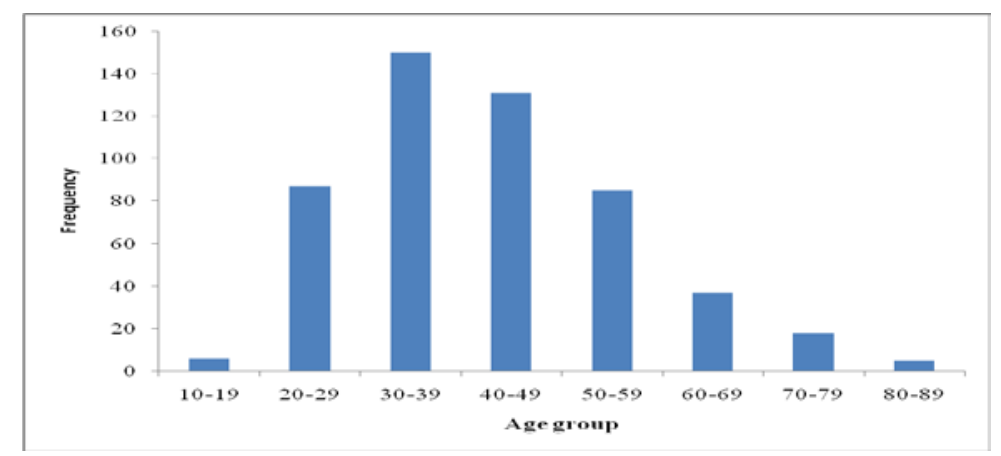

Fig. 1. Graph showing the age distribution (in years) of the respondents. 


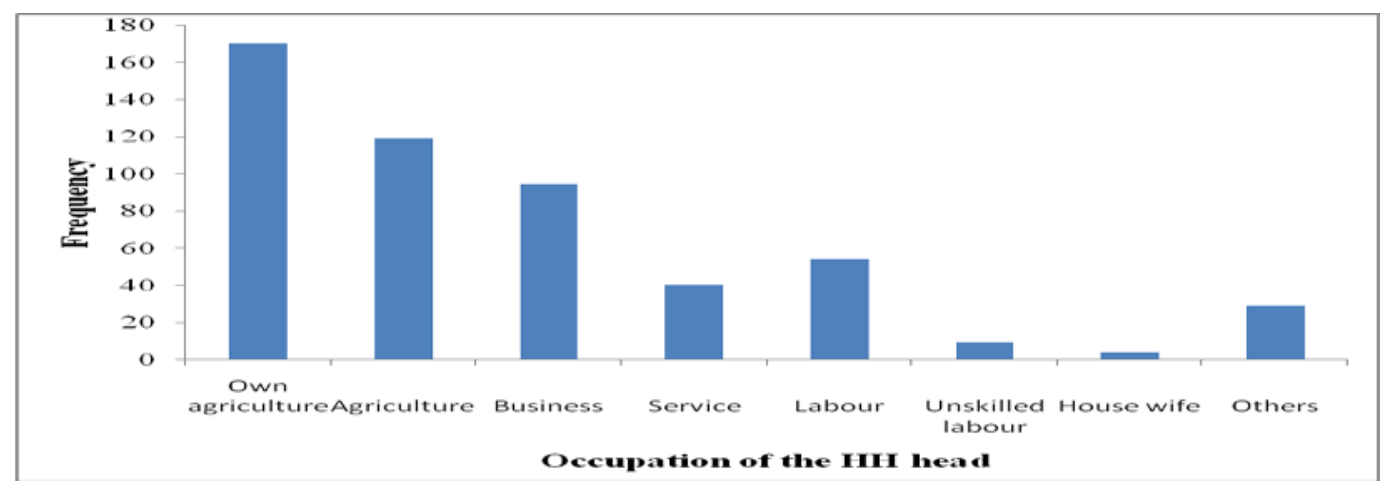

Fig. 2. Graph showing the frequency of the occupation of the house-hold heads.

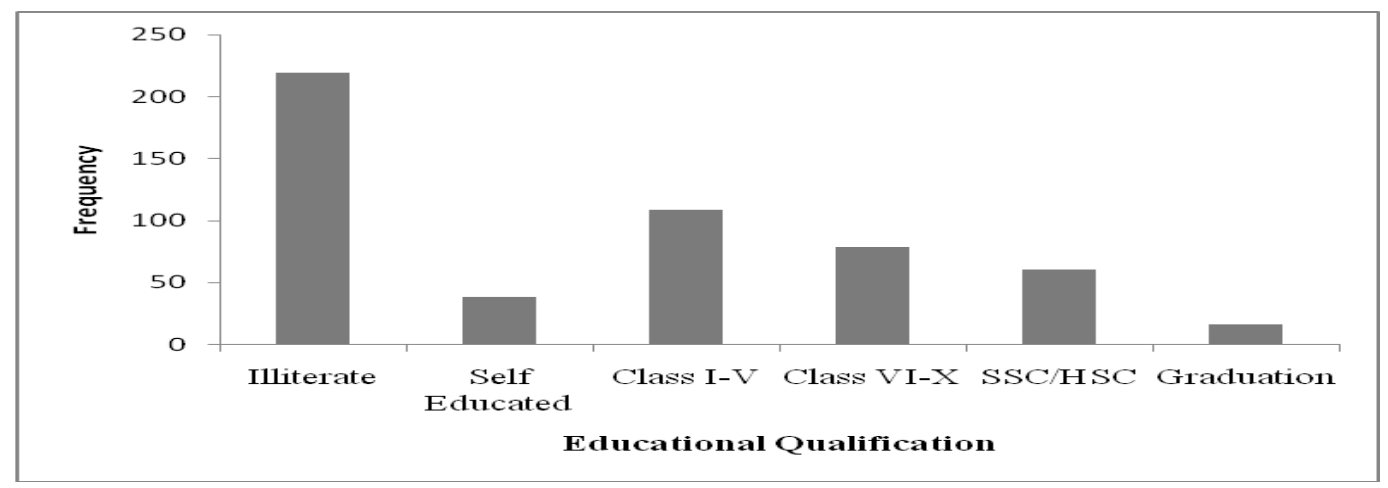

Fig. 3. Graph showing the educational qualification of the respondent

Table 1. House types according to category in the study area.

\begin{tabular}{lllll}
\hline & House types & Frequency & Percent & Valid Percent \\
\hline Valid & Mud House & 184 & 35.5 & 35.5 \\
& Thatch House & 86 & 16.6 & 16.6 \\
& Tin & 33.9 & 33.9 \\
Brick House & 65 & 12.5 & 12.5 \\
Other & 8 & 1.5 & 1.5 \\
Total & 519 & 100.0 & 100.0 \\
\hline
\end{tabular}

Table 2. Distance of cattle shed from their living room.

\begin{tabular}{lllll}
\hline & Distance & Frequency & Percent & Valid Percent \\
\hline Valid & Up to 20 ft & 282 & 54.3 & 57.3 \\
& Up to 20-50 ft & 45 & 8.7 & 9.1 \\
& More than $50 \mathrm{ft}$ & 1 & .2 & .2 \\
& NA & 164 & 31.6 & 33.3 \\
& Total & 492 & 94.8 & 100.0 \\
Missing & 0 & 27 & 5.2 & \\
Total & & 519 & 100.0 & \\
\hline
\end{tabular}


The distance of the cattle shed from the household, within $20 \mathrm{ft}$ were $57.3 \%$ while, up to $20-50 \mathrm{ft}$ were $9.1 \%$ only (Table 2). The inhabitants, in these rural areas, who have not heard about the kala-azar were in a great percentage $(87.1 \%)$ and only $12.5 \%$ of the totals heard about kala-azar (Table 3 ); $57 \%$ of them use mosquito nets, and $28.5 \%$ use coil or mat, very few $(5.1 \%)$ use smoke (Fig. 4)). Regarding the utilization of mosquito nets, in $76.5 \%$ households use for all members, $22.5 \%$ for some of the members (Fig. 5).

Among the professionals, about $80.4 \%$ of them had the correct knowledge regarding the specific agent Leishmania donovani of kala-azar, $5.4 \%$ said Plasmodium falciparum and 3.3\% said Wuchereria bancrofti is the specific agent of kala-azar (Fig: 6). To assess the knowledge of the professionals, it has been observed that, about $40.7 \%$ of them believed that flies are the reservoir of kalaazar, while, $34.1 \%$ believed man is reservoir and $17.6 \%$ believe reservoir is mosquito (Table 4). Out of 16 RMO, 8 believe flies, 6 for man and out of 15 Senior Nurses, 4 think mosquito, 4 for flies, 4 for man and 1 for rat. Out $\mathrm{f} 13$ Medical Assistant- UHC, 7 think flies are reservoir for kala-azar, 4 for man and 1 for mosquito (Table 4). About $84.8 \%-85.9 \%$ professionals said pyrexia and spleen enlargement are the most prominent clinical features of kala-azar, while, $63 \%-69.6 \%$ have concept about weight loss, anaemia, liver enlargement and skin discoloration as clinical features of kala-azar (Table 6).

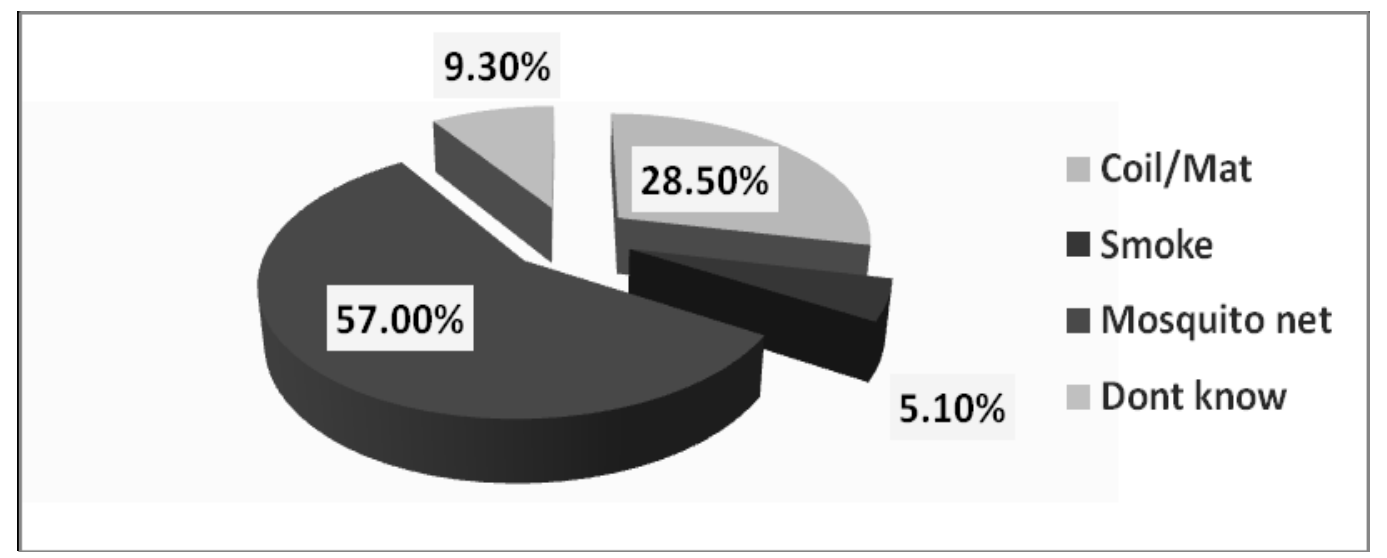

Fig. 4. Distribution of respondents regarding their knowledge about avoiding the bite of sand fly. 


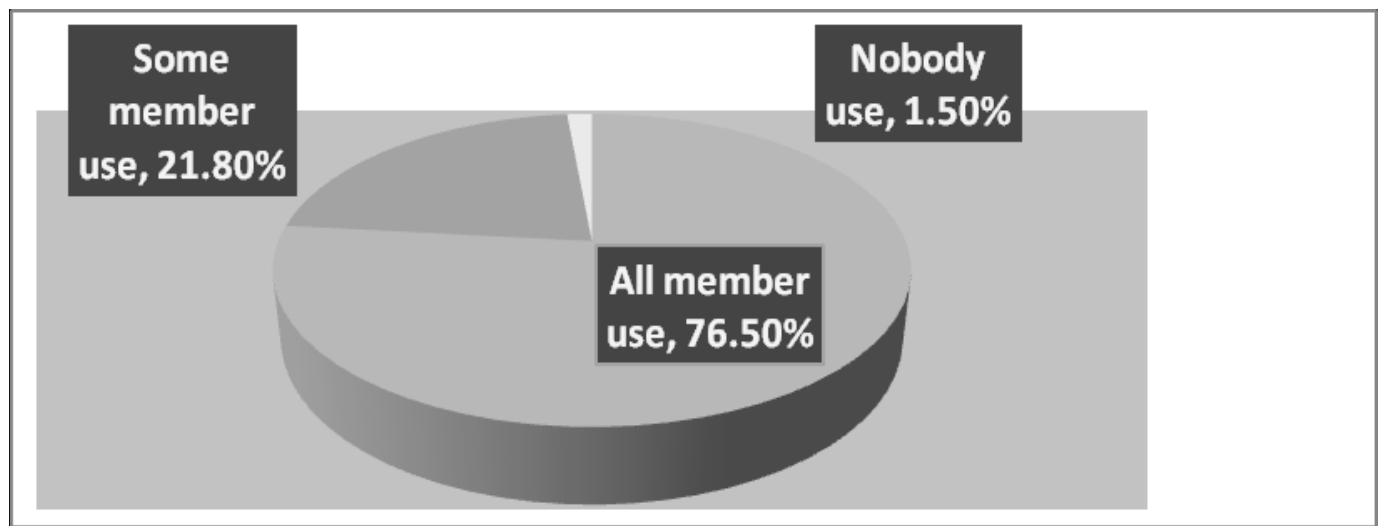

Fig. 5. Percentage of the respondents according to the utilization of mosquito net among the family members.

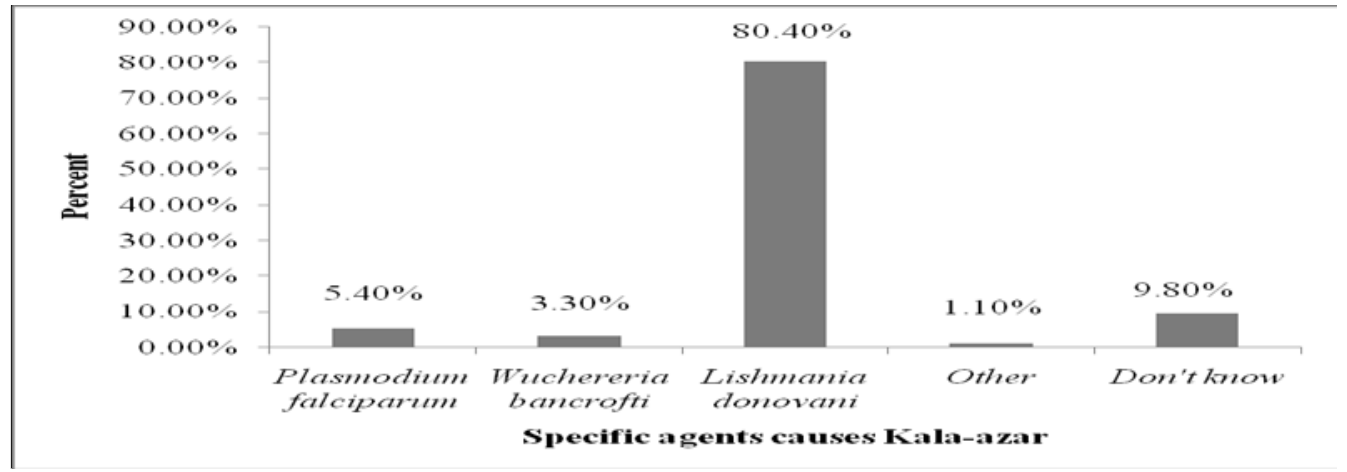

Fig. 6. The knowledge of professionals about the agent of Kala-azar.

Table 3. Respondents awareness (\%) in different field related with Kalaazar.

\begin{tabular}{lc}
\hline & Yes \\
\hline $\begin{array}{l}\text { Percentage of respondents according to whether they have heard the } \\
\text { name of kala-azar or not }\end{array}$ & $79.2 \%$ \\
$\begin{array}{l}\text { Percentage of respondents regarding the knowledge about whether } \\
\text { kala-azar is curable or not. }\end{array}$ & $65.4 \%$ \\
$\begin{array}{l}\text { Percentage of respondents according to whether they have heard } \\
\text { about sand fly. }\end{array}$ & $12.5 \%$ \\
\hline
\end{tabular}


Table 4. The knowledge of professionals regarding the reservoir of Kala-azar in humans.

\begin{tabular}{lccc}
\hline & Knowledge on & Frequency & Percent \\
\hline & Mosquito & 16 & 17.4 \\
& Flies & 37 & 40.2 \\
& Man & 31 & 33.7 \\
& Rat & 1 & 1.1 \\
& Other & 6 & 6.5 \\
& Total & 91 & 98.9 \\
Missing & 99 & 1 & 1.1 \\
Total & & 92 & 100.0 \\
\hline
\end{tabular}

Table 5. Category of professionals the knowledge regarding the transmission of Kala-azar.

\begin{tabular}{|c|c|c|c|c|c|c|c|}
\hline & \multirow[t]{2}{*}{ Category } & \multicolumn{5}{|c|}{ Reservoir for Kala-azar } & \multirow[t]{2}{*}{ Total } \\
\hline & & Mosquito & Flies & Man & Rat & Other & \\
\hline Designation/ & UHFPO & 1 & 3 & 9 & 0 & 0 & 13 \\
\hline \multirow[t]{7}{*}{ Job details } & RMO & 2 & 8 & 6 & 0 & 0 & 16 \\
\hline & MO & 1 & 6 & 4 & 0 & 3 & 14 \\
\hline & Senior nurse & 4 & 4 & 4 & 1 & 2 & 15 \\
\hline & SACMO & 1 & 5 & 2 & 0 & 0 & 8 \\
\hline & Medical & & & & & & \\
\hline & $\begin{array}{l}\text { Assistant-UHC } \\
\text { Medical }\end{array}$ & 1 & 7 & 4 & 0 & 1 & 13 \\
\hline & istant-USC & 6 & 4 & 2 & 0 & 0 & 12 \\
\hline Total & & 16 & 37 & 31 & 1 & 6 & 91 \\
\hline
\end{tabular}

Most of the UHFPO, RMO and MO understand that severe anaemia and ultimately death are the consequences of not treating of kala-azar. Commonly, $73.9 \%$ think that severe anaemia is the consequences of not treating of kalaazar. About $21.7 \%-53.3 \%$ of the professionals have knowledge that loss of skin sensation, renal failure, cachexia and hepatic fever are the consequences of not treating kala-azar (Table 7). 
Table 6. Knowledge of professionals about clinical features of Kala-azar.

\begin{tabular}{lccc}
\hline Clinical features & \multicolumn{3}{c}{ Cases } \\
\cline { 2 - 4 } & Valid & Missing & Total \\
\cline { 2 - 4 } & $\mathbf{N}$ & Percent & N \\
\hline Pyrexia & 78 & $84.8 \%$ & 14 \\
Abdominal swelling & 49 & $53.3 \%$ & 43 \\
Weight loss & 64 & $69.6 \%$ & 28 \\
Anemia & 56 & $60.9 \%$ & 36 \\
Spleen enlargement & 79 & $85.9 \%$ & 13 \\
Liver enlargement & 61 & $66.3 \%$ & 31 \\
Skin discoloration & 58 & $63.0 \%$ & 34 \\
Bloody diarrhea & 5 & $5.4 \%$ & 87 \\
Lymph node swelling & 33 & $35.9 \%$ & 59 \\
\hline
\end{tabular}

Table 7. Professional's knowledge regarding the consequences if not treating Kala-azar.

\begin{tabular}{|c|c|c|c|c|c|}
\hline & & & & \multicolumn{2}{|c|}{ Cases } \\
\hline & \multicolumn{3}{|c|}{ Valid } & \multicolumn{2}{|c|}{ Missing } \\
\hline & $\mathbf{N}$ & Percent & $\mathbf{N}$ & Percent & Percent \\
\hline Spontaneous cure & 9 & $9.8 \%$ & 83 & $90.2 \%$ & $100.0 \%$ \\
\hline Hepatic failure & 49 & $53.3 \%$ & 43 & $46.7 \%$ & $100.0 \%$ \\
\hline Valvular heart disease & 8 & $8.7 \%$ & 84 & $91.3 \%$ & $100.0 \%$ \\
\hline Severe anemia & 68 & $73.9 \%$ & 24 & $26.1 \%$ & $100.0 \%$ \\
\hline Renal failure & 22 & $23.9 \%$ & 70 & $76.1 \%$ & $100.0 \%$ \\
\hline Cachexia & 38 & $41.3 \%$ & 54 & $58.7 \%$ & $100.0 \%$ \\
\hline Loss of skin sensation & 20 & $21.7 \%$ & 72 & $78.3 \%$ & $100.0 \%$ \\
\hline Dementia & 4 & $4.3 \%$ & 88 & $95.7 \%$ & $100.0 \%$ \\
\hline Death & 68 & $73.9 \%$ & 24 & $26.1 \%$ & $100.0 \%$ \\
\hline
\end{tabular}


Table 8. Knowledge of professionals regarding the drug are used for treatment of Kala-azar.

\begin{tabular}{llll}
\hline & Drug & Frequency & Percent \\
\hline Valid & Chloroquine & 1 & 1.1 \\
& SAG & 79 & 85.9 \\
& Metronidazole & 2 & 2.2 \\
& Parmomycin & 2 & 2.2 \\
& Eiethylcarbamazine & 1 & 1.1 \\
& Miltefosine & 3 & 3.3 \\
& Amphotericin B & 2 & 2.2 \\
& Total & 90 & 97.8 \\
Missing & & 2 & 2.2 \\
Total & & 92 & 100.0 \\
\hline
\end{tabular}

The present investigation revealed that, about $87.8 \%$ of the professionals understand that SAG is the drug should be used for treatment of kala-azar (Table 9), while, $1.1 \%-3.3 \%$ of the professionals support the application of Eiethylcarbamazine, Miltefosine, Metronidazole and Parmomycin drugs are used for kala-azar (Table 8). Kala-azar or visceral leishmaniasis is a vector-borne parasitic disease that affects the cells of the mononuclear phagocytic system (MPS) of the body of human. In Bangladesh, increasing trend of incidence of kala-azar is observed. Most prevalent areas are Sirajganj, Pabna, Tangail and Mymenshingh (Alam et al. 2009, Musa and Khanum 2009).

In Bangladesh, the situation of kala-azar tensed to be epidemic in multiple foci and inter-epidemic period used to be every 15-20 years interval. So it need muss sero-survey and control program to avoid the kala-azar epidemic problem. Visceral leishmaniasis can be complicated by serious secondary bacterial infections such as pneumonia, dysentery and pulmonary tuberculosis, which often contribute to the high fatality rate of patients. Others complications include hemolytic anemia, acute renal damage and severe mucosal hemorrhage (WHO expert committee report, 1991). The incubation period is highly variable; the disease can appear anytime between ten days to over one year (Bern and Chowdhury 2006, Hasan et al. 2010). Kala-azar has a high mortality rate and gives rise to important public health problems ((Manson, 1982, Thakur 1984, Khanum et al. 2008). The majority of cases are reported in the age group 5 to 30 years. The ratio of prevalence among male and female was 2:1 (Masum and Chowdhury 1996).

In case of sand fly, the environment management methods for control are generally directed at the elimination of breeding sites in and around house. The breeding habitats though difficult to locate and destroy. The places around houses and cattle sheds should be kept clean and plastered at regular intervals. The cattle shed, lose soil and organic materials should be removed daily (Hasan et al. 2010). 
The present study has been done to assess the basic concept and knowledge regarding the disease kala-azar, its sign and symptoms, mode of transmission, prevention, vector control and course of treatment for kala-azar. It is expected that, the findings of the present study will contribute to future planning for development of knowledge, training of the professionals and health workers, prevention and control of kala-azar in endemic areas of Bangladesh. More efforts should be given by the Government and health workers should be given efforts to raise the awareness about kala-azar in the communities.

\section{LITERATURE CITED}

ALAM, M. S, YAGATSUMA, Y., MONDAL, D., KHANUM, H. and HAQUE, R 2009. Relationship between sand fly fauna and kala-azar endemicity in Bangladesh. Acta Tropica 112: 23-25.

BERN, C. and CHOWDHURY, R. 2006. The epidemiology of visceral leishmaniasis in Bangladesh: prospects for improved control. Indian Journal of Medical Research. 123: $275-288$.

BERN, C., HAQUE, R., CHOWDHURY, R., ALI, M. and KURKJIAN, K.M. 2007. The epidemiology of visceral leishmaniasis and asymptomatic leishmanial infection in a highly endemic Bangladeshi village. American Journal of Tropical Medicine and Hygiene, 76: 909-914.

CHATERJEE, K.D. 1995. Parasitology, Protozoology and Helminthology. 12 $2^{\text {th }}$ edition. Chaterjee Medical Publishers, Calcutta: pp. 238.

HOSSAIN, S.Z., HOQUE, A., and ALAM, M. 1994. Clinical Profile of Kala-azar in Patuakhali, prospective study of 30 patients during one year. TAS, 4: 5-12.

HASAN, M.S, KHANUM, H. and EASMIN, F 2010. Prevalence of Leishmaniasis in Trishal, Mymensing: Relation with blood group, Age group and associated clinical disorders. Bangaldesh J. Zool. 37 (2): 239- 246.

KHANUM, H., MASUM, MA., KABIR, R., DAY, R R. and FARHANA, R. 2008. Comparison of Direct Agglutination Test(DAT) and aldehyde Test (AT) in serodiagnosis of visceral leishmaniasis. Bangladesh J. Zool. 36(1):93-99.

PODDER, M.P., KHANUM, H., ALAM, M. S. KHAN, M. G. M., HAQUE, R. and ELAHI, R. 2010. Comparison of Urine based ELISA and rK39 Dipstick Test for detection of Kalaazar. Bangladesh J. Zool. 39(1): 11-18.

MANSON, B.P.E.C. 1982. Leishmaniasis In Manson Bahr PEC and Tropical Disease. $18^{\text {th }}$ ED. ELBS and Bailliere-Tindall. London: pp. 93-115.

MASUM, M.A., CHOWHURY, M.S., AHMED, R.U. and MIA, M.A.H.1996. Outbreak of Visceral Leishmaniasis in Thakurgaon, Bangladesh. Journal of Preventive and Social Medicine, 4-9(2):38-44.

MONDAL D., ALAM M.S., KARIM Z., HAQUE R., BOELAERT M., AND KROEGER A., 2008. Present situation of vector control management in Bangladesh: a wakeup call," Health Policy, 87(3):369-376.

MUSA, S. and KHANUM, H. 2009. Post kala-azar dermal leishmaniasis (PKDL) in two kalaazar endemic areas of Bangladesh. Bangladesh J. Zool. 37(2): 113- 120.

RAHMAN, K.M. and ISLAM, N. 1989. Resurgence of Visceral Leishmaniasis in Bangladesh Bull Who. 61: 113-116. 
RAHMAN, H.M. 1983. Treatment and Prevention of Kala-azar - A Review Journal of Dhaka Medical College. 3(1): 27-30.

SHANMUGHAM, C.A.K., ROY, R.G. and GANESAN, A.V. 1977. Kala-azar in Tamil Nadu State during 1945-75 a retrospective and prospective study. Indian J. Med. Res. 65: 796-806.

SHIDDO, S.A., MOHAMED, A.A., AKUFFO, H.O., MOHAMUD, K.A., HERZI, A.A., HERZI, M.H., HULDT, G., NILSON, L.A., OUCHTERLONY, O. and THORSTENSSON, R. 1995. Visceral Leishmaniasis in Somalia: prevalence of markers of infection and disease manifestations in a village in an endemic area. Transactions of the Royal Society of Tropical Medicine and Hygiene. 89(4): 361-365.

THAKUR, C.P. 1984. Epidemiological, Clinical, and Therapeutic features of Bihar Kalaazar (including post kala-azar dermal leishmaniasis). Transactions of the Royal society of Tropical Medicine and Hygiene. 78: 391-398.

WORLD HEALTH ORGANIZATION. 1993. Control of Tropical Disease The Leishmaniasis. 8.

WORLD HEALTH ORGANIZATION and INSTITUTE OF EPIDEMIOLOGY DISEASE CONTROL and RESEARCH. 1991. Visceral leishmaniasis and its control. 1-57.

(Manuscript received on 12 August, 2015; revised on 28 December, 2015) 